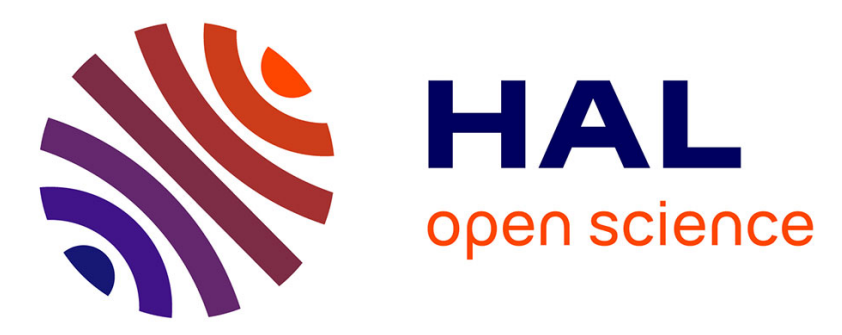

\title{
Low Saturation Fluence Antiresonant Quantum Dot SESAMs for MIXSEL integration
}

Yohan Barbarin, A.-R. Bellancourt, D. J H C Maas, M. Shafiei, M. Hoffmann, M. Golling, T. Südmeyer, U. Keller

\section{- To cite this version:}

Yohan Barbarin, A.-R. Bellancourt, D. J H C Maas, M. Shafiei, M. Hoffmann, et al.. Low Saturation Fluence Antiresonant Quantum Dot SESAMs for MIXSEL integration. Conference on Lasers and Electro-Optics, 2009, Baltimore, United States. pp.CThO4, 10.1364/CLEO.2009.CThO4 . hal02549341

\section{HAL Id: hal-02549341 \\ https://hal.science/hal-02549341}

Submitted on 24 Apr 2020

HAL is a multi-disciplinary open access archive for the deposit and dissemination of scientific research documents, whether they are published or not. The documents may come from teaching and research institutions in France or abroad, or from public or private research centers.
L'archive ouverte pluridisciplinaire HAL, est destinée au dépôt et à la diffusion de documents scientifiques de niveau recherche, publiés ou non, émanant des établissements d'enseignement et de recherche français ou étrangers, des laboratoires publics ou privés. 


\title{
Low Saturation Fluence Antiresonant Quantum Dot SESAMs for MIXSEL integration
}

\author{
Y. Barbarin, A. R. Bellancourt, D. J. H. C. Maas, M. Shafiei, M. Hoffmann, M. Golling, T. Südmeyer, and \\ U. Keller \\ Department of Physics, Institute of Quantum Electronics, ETH Zurich, Wolfgang-Pauli-Str. 16, 8093 Zurich, Switzerland. \\ barbarin@phys.ethz.ch
}

\begin{abstract}
:
A detailed QD-SESAM growth study enabled the first modelocking of a VECSEL with similar spot size on gain and antiresonant SESAM. Antiresonant designs can strongly improve MIXSELs, a novel type of ultrafast integrated VECSELs.
\end{abstract}

OCIS codes: (140.4050) Mode-locked lasers; (320.7080) Ultrafast devices

\section{Introduction and motivation}

Vertical external cavity surface emitting lasers (VECSELs) combine the benefits from diode-pumped solid state and semiconductor laser technologies with wavelength flexibility, high power and excellent beam quality. Previously, ultrafast VECSELs required a folded cavity with a separate semiconductor saturable absorber mirror (SESAM) for passive modelocking. Recently, we demonstrated that SESAM and VECSEL gain structure can be integrated into a single semiconductor structure (Figure 1a), which is referred to as modelocked integrated external-cavity surface emitting laser (MIXSEL, [1]). The compact and simple MIXSEL platform has a high potential for numerous applications such as the optical clocking of multi-core microprocessors. Inside the MIXSEL chip, the beam diameter on gain and absorber layers are the same (1:1 modelocking). For achieving stable modelocking, the absorber has to saturate faster than the gain, i.e. its saturation fluence should be lower than for the gain. This was achieved by using one QD-saturable absorber layer placed in a resonant field enhancement (Figure 1b). However, such resonant enhancement leads to high group delay dispersion and sensitivity towards growth errors (Figure 1d), which explains the relatively long pulse duration of the first MIXSEL (32 ps).

In this work, we demonstrate for the first time that an antiresonant SESAM can modelock a VECSEL with similar spot size on gain and saturable absorber. This has been made possible thanks to a systematic study on the influence of QD-SESAMs growth parameters and post-growth annealing on the macroscopic optical SESAM properties [2]. We experimentally confirmed the design guidelines and present an optimized multiple-layer QDSESAM, which achieves low saturation fluence without any resonant field enhancement. Such designs will enable MIXSELs with high growth tolerance and low dispersion (Figure 1c and Figure 1e), which is especially important for meeting the manufacturing requirements of large scale applications.

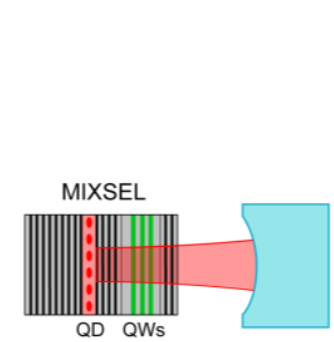

a)

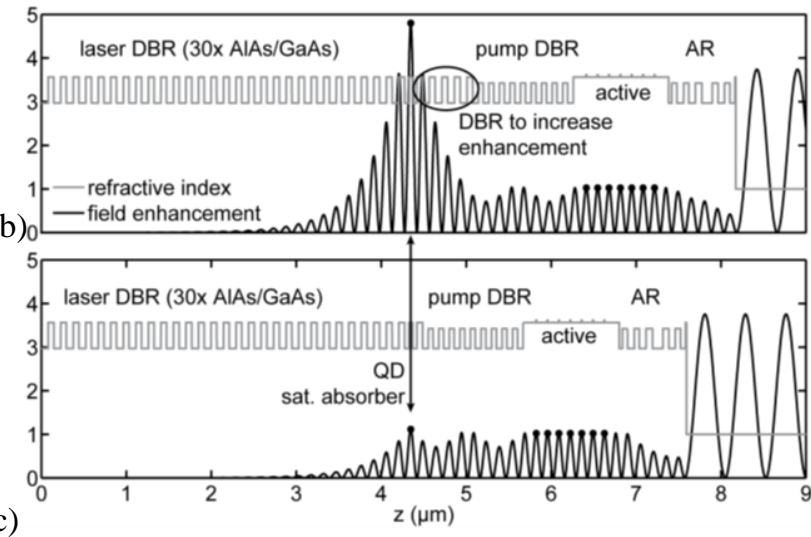

d)

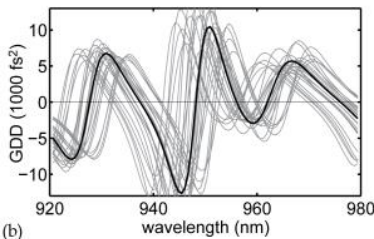

e) (b)

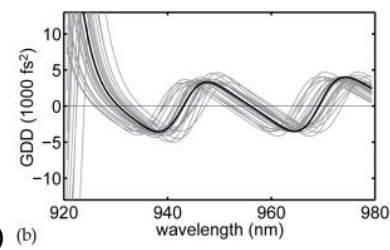

Figure 1: a) MIXSEL concept b) Field enhancement (black) and refractive indices for the different layers of the MIXSEL structure (grey). The graph shows the current resonant MIXSEL design with a 5-pair intermediate DBR for field enhancement and c) the antiresonant design. d) Group delay dispersion (GDD) of the resonant design and e) the antiresonant design for random growth errors all below $1 \%$. 


\section{Antiresonant QD-SESAMs with low saturation fluence}

Quantum dot absorbers have received much attention because of their fast relaxation and their large design freedom $[3,4]$. Very recently, we presented the first detailed study on the effects of growth parameters and post-growth annealing on the macroscopic optical properties of single layer QD-SESAM. We experimentally demonstrated that the modulation depth can be tuned with the ML coverage (i.e. QD density), while the saturation fluence is constant. It is possible to reduce the saturation fluence with post-growth annealing. Depending on the annealing time and temperature, we could reduce the saturation fluence of QD-SESAMs up to a factor of ten [2].

The modulation depth of the annealed single layer antiresonant QD-SESAMs is on the order of $0.5 \%$, which is too low for VECSEL modelocking. We therefore increased the number of absorber layers and experimentally confirmed that the modulation depth is proportional to the number of layers, while the saturation fluence still remains constant. The influence of annealing is similar to single-layer QD-SESAMs, the saturation fluence can be tuned by the annealing temperature. Figure 2a shows the annealing of QD-SESAMs with 4 QD layers with about $2 \mathrm{ML}$ Indium coverage grown at $420^{\circ} \mathrm{C}$.

For the first time, 1:1 modelocking has been demonstrated using an antiresonant QD-SESAM, i.e. without field enhancement in the QD-absorber. The QD-SESAM with 4 QD layers was grown with two double layers placed in two subsequent antinodes of the electric field. The sample annealed at $675^{\circ} \mathrm{C}$ for one hour showed the best modelocking performances. It has a modulation depth of $2.3 \%$ and $24 \mu \mathrm{J} / \mathrm{cm}^{2}$ saturation fluence. Pulses of $18 \mathrm{ps}$ have been obtained at $2.75 \mathrm{GHz}$ and $56 \mathrm{~mW}$ output power (Figure 2c).

\begin{tabular}{|c|c|c|}
\hline $\begin{array}{c}\text { 4-layers } \\
\text { QD-SESAM } \\
\text { Annealing }\end{array}$ & $\begin{array}{c}F_{\text {sat }} \\
\left(\mu \mathrm{J} / \mathrm{cm}^{2}\right)\end{array}$ & \multicolumn{1}{|c|}{$\Delta R(\%)$} \\
\hline As grown & 81 & 2.2 \\
\hline $600^{\circ} \mathrm{C}$ & 73 & 2 \\
\hline $625^{\circ} \mathrm{C}$ & 61 & 1.9 \\
\hline $675^{\circ} \mathrm{C}$ & 24 & 2.3 \\
\hline $685^{\circ} \mathrm{C}$ & 20 & 1.9 \\
\hline
\end{tabular}

a)

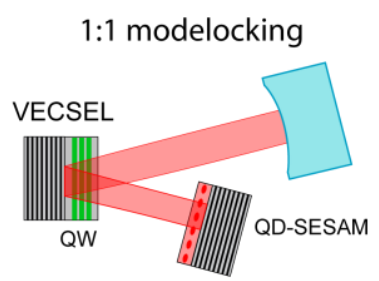

b)

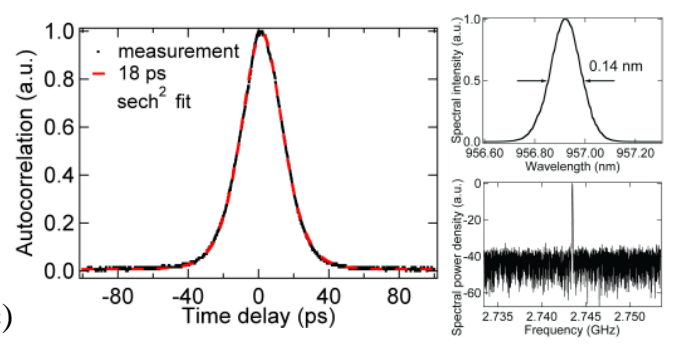

c)

Figure 2: a) Saturation fluence, modulation depth and nonsaturable losses of the 4-layers QD-SESAM grown at $420^{\circ} \mathrm{C}$. b) SESAM-VECSEL1:1 modelocking. c) Pulse characterization of the modelocking result with $56 \mathrm{~mW}$ average output power. Left: autocorrelation with sech ${ }^{2}$-fit, right: optical spectrum and RF spectrum on a 20-MHz span with $100-\mathrm{kHz}$ resolution bandwidth.

\section{Conclusions and Outlook}

By studying the effect of growth parameters and post-growth annealing on the macroscopic optical properties of QD-SESAM, we realized the first antiresonant low saturation fluence QD-SESAM for VECSEL modelocking. We experimentally demonstrated that the modulation depth can be tuned with the ML coverage (i.e. QD density) and the number of QD layers, while the saturation fluence is constant, as predicted by theory. Post-growth annealing allows a reduction of the saturation fluence.

For the first time, we achieve modelocking with similar mode areas on the VECSEL and the SESAM with an antiresonant absorber design. The antiresonant design is very promising for increasing the repetition rate and reducing the pulse duration of passively modelocked ultrafast VECSELs, as the antiresonant design has a lower dispersion. Moreover, it can substantially simplify MIXSEL designs. The growth tolerance will be greatly increased without the resonant field enhancement in the absorber.

\section{References}

[1] D. J. H. C. Maas, A.-R. Bellancourt, B. Rudin, M. Golling, H. J. Unold, T. Südmeyer, and U. Keller, "Vertical integration of ultrafast semiconductor lasers," Appl. Phys. B, vol. 88, pp. 493-497, 2007.

[2] D. J. H. C. Maas, A. R. Bellancourt, M. Hoffmann, B. Rudin, Y. Barbarin, M. Golling, T. Südmeyer, and U. Keller, "Growth parameter optimization for fast quantum dot SESAMs," Opt. Express, vol. 16, pp. 18646-18656, 2008.

[3] E. U. Rafailov, S. J. White, A. A. Lagatsky, A. Miller, W. Sibbett, D. A. Livshits, A. E. Zhukov, and V. M. Ustinov, "Fast quantumdot saturable absorber for passive mode-locking of solid-state lasers," IEEE Photonics Technology Letters, vol. 16, pp. 2439-2441, 2004.

[4] D. Lorenser, H. J. Unold, D. J. H. C. Maas, A. Aschwanden, R. Grange, R. Paschotta, D. Ebling, E. Gini, and U. Keller, "Towards Wafer-Scale Integration of High Repetition Rate Passively Mode-Locked Surface-Emitting Semiconductor Lasers," Appl. Phys. B, vol. 79, pp. 927-932, 2004. 